\title{
ANÁLISE DE MÉTODOS NO ENSINO DE GEOGRAFIA
}

\author{
Bruno da Silva Santos \\ Aluno do $3^{\circ}$ período de Geografia da UFRN \\ Marco Aurélio de Lima \\ Aluno do $3^{\circ}$ período de Geografia da UFRN \\ Reginaldo Lopes Santana \\ Aluno do $3^{\circ}$ período de Geografia da UFRN
}

\section{Resumo}

O presente estudo traz uma análise de como o livro didático usa os métodos científicos hipotéticos- dedutivo dialético e hermenêutico-fenomenológico para trabalhar o seu conteúdo em sala de aula voltado para o ensino de jovens e adultos. Este artigo reflete sobre a importância da escolha do método a ser utilizado para se abordar os assuntos propostos no livro didático, levando em consideração o seu público alvo, adequando sua metodologia de ensino aos alunos para garantir uma melhor comunicação e desta maneira uma melhor aprendizagem. Neste material iremos apresentar considerações e sugestões de atividades para serem realizadas nas três abordagens científicas- metodológicas utilizadas pelo livro didático analisado, no ensino da geografia escolar para educação de jovens e adultos.

Palavras-Chaves: Livro Didático. Método Científico. EJA.

\begin{abstract}
The present study provides an analysis of how the textbook uses the hypothetical scientific-deductive dialectic and hermeneutic-phenomenological methods to work its classroom content aimed at teaching young people and adults. This article reflects on the importance of choosing the method to be used to approach the subjects proposed in the textbook, taking into account its target audience, adapting its teaching methodology to students to ensure better communication and thus better learning. In this material we will present considerations and suggestions of activities to be carried out in the three scientific-methodological approaches used by the textbook analyzed, in the teaching of school geography for youth and adult education.
\end{abstract}

Keywords: Didactic Book. Scientific Method. EJA. 


\section{INTRODUÇÃO}

Presume-se que a abordagem teórica de um livro didático para o ensino, tem como objetivo influenciar a prática docente e assim alcançar certos resultados de aprendizagem dos alunos. Para realizar este estudo, foi escolhido o livro didático da coleção Viver e Aprender: Ciências humanas, Tempos, Espaço e Cultura, para ensino médio. Os autores do livro são Ana Paula Corti; André Luis Pereira dos Santos; Denise Mendes; Maria Carla Corrochano; Maria Lidea Bueno Fernandes; Roberto Catelli JR. e Roberto Giassanti. Este livro trabalha as ciências humanas: Filosofia, Sociologia, História e Geografia. A análise foi feita nos capítulos relacionados ao ensino da geografia.

Este artigo traz a discussão sobre o ensino para jovens e adultos, o melhor método de ensino para ser aplicado, como a abordagem vai contribuir para a didática em sala de aula e de como ela contribuirá na aprendizagem dos alunos. Além disso, serão apresentadas considerações e sugestões para o ensino geográfico nas três abordagens cientificometodológico utilizado pelo livro com ênfase na instrução de jovens e adultos. Para Sauer, o estudo da geografia se relaciona com o ser, onde "a cultura é o agente, a área natural é o meio, a paisagem cultural é o resultado." (SAUER, 1983. p. 343).

Este artigo foi dividido em cinco seções, cada uma delas buscará trabalhar a análise realizada de forma simples e direta, para facilitar a compreensão do estudo. Primeiramente será explicado o que é o EJA (Educação de jovens e adultos), quais são os indivíduos que o compõem e quais são os seus objetivos; A segunda seção deste texto irá falar sobre o livro didático e como o PNLD (Programa Nacional do Livro Didático) contribui e influencia no processo de confecção dos livros didáticos de nosso país.

Na terceira seção serão apresentadas as principais características dos métodos e quais deles foram trabalhados no livro analisado; visando amenizar a dificuldade de alguns docentes da forma de lidar com cada tipo de método científico em sala de aula; na quarta seção serão trazidas discussões e sugestões de como abordar os temas propostos nos livros nas três metodologias científicas, para auxiliar na prática do ensino da geografia. Na quinta e última seção deste trabalho, serão dadas as considerações finais sobre a análise realizada no ensino de geografia e a importância de se fazer a escolha correta do livro didático que iremos utilizar em sala de aula.

\section{SOBRE O EJA E SEUS ALUNOS}

O EJA (Educação de Jovens e Adultos) é um método de ensino baseado no modelo convencional de ensino, tem o objetivo de ombrear estudantes, que por motivos quaisquer, perderam o nivelamento com os anos escolares que estão de acordo com sua faixa etária. Regulado pela lei $n^{\circ}$ 9394, de 20 de dezembro de 1996, o EJA permite que os estudantes matriculados nesta modalidade concluam um ano letivo por semestre, ou seja, permite uma conclusão mais acelerada para os egressos, sendo assim, dá mais oportunidades para quem não teve a chance de concluir seus estudos na idade apropriada.

Os alunos desta modalidade são, em sua maioria, adultos de várias idades que estão retornando à sala de aula para concluir o ensino médio por diversos motivos, seja para ter uma melhor qualificação profissional ou apenas para concluir seus estudos. Devido a esta grande variedade de alunos de várias idades e com experiências de vidas distintas, além de vários deles já estarem incluídos no mercado de trabalho é cada vez mais difícil e importante que o professor aplique o método de ensino mais adequado para abordar os 
assuntos que serão discutidos em sala de aula. Segundo Gadotti et al (2001), a educação de jovens e adultos integra vários processos educativos como "a do conhecimento, das práticas sociais, do trabalho, do confronto de problemas coletivos e da construção da cidadania" (GADOTTI e ROMÃO, 2001, p. 119).

\section{SOBRE O LIVRO DIDÁTICO E PROGRAMA NACIONAL DO LIVRO DIDÁTICO}

Os livros didáticos são ferramentas de apoio pedagógico, não obrigatório, utilizadas em toda a vida escolar do estudante desde os anos primários até o fim do ensino médio. São baseados a partir dos livros tradicionais, mas com o objetivo de orientar o professor na prática do ensino e ajudar no aprendizado dos estudantes; nas escolas públicas do Brasil a escolha, distribuição e provimento dos livros didáticos são regimentados pelo Programa

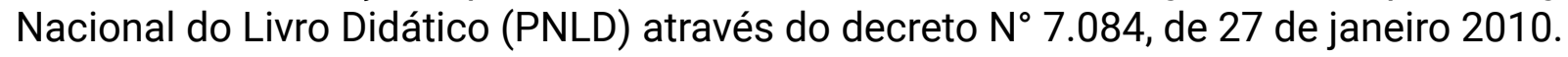

De forma mais detalhada, O PNLD é responsável pela distribuição gratuita de livros didáticos em escolas inscritas no programa, a escolha dos livros é responsabilidade da instituição, desde que tenham sido aprovados e estejam de acordo com o programa. A distribuição e escolha dos livros acontecem em ciclos de 3 anos, como os livros são utilizados no modelo não-consumível, devem ser repassados para um novo aluno daquele nível no próximo ano letivo e assim por diante até o fim do ciclo quando novos livros trienais serão distribuídos. A aprovação dos livros no programa, bem como a escolhas dos dicionários e enciclopédias são responsabilidade do Ministério da Educação através de editais publicados no Diário Oficial da União (DOU).

\section{APLICAÇÃO DOS MÉTODOS NA DIDÁTICA DO LIVRO}

Para se entender como o livro faz uso dos métodos científicos na didática utilizada no seu conteúdo, é preciso primeiramente saber o que é método e também é necessário saber as características dos três métodos encontrados no livro, que são os métodos hipotéticodedutivos; hermenêutico-fenomenológico e o método dialético. 0 método científico é o conjunto das normas básicas que devem ser seguidas para a produção de conhecimentos que têm o rigor da ciência, ou seja, é um método usado para a pesquisa e comprovação de um determinado conteúdo. $\mathrm{Na}$ análise do livro foi possível identificar a presença de três métodos científicos.

0 método hipotético-dedutivo, que tem como principal característica a investigação científica. Este método visa construir e testar uma possível resposta ou solução para um problema. Este método vê o processo do conhecimento como consequência do simples registro das impressões sensoriais, que, com auxílio da lógica, dava origem às leis e teorias, ele utiliza dados científicos como base para chegar a determinadas conclusões. Para utilizar o método Hipotético-Dedutivo, o autor do livro faz uso de gráficos "pizza" e de mapas temáticos como podemos ver nos exemplos abaixo: 


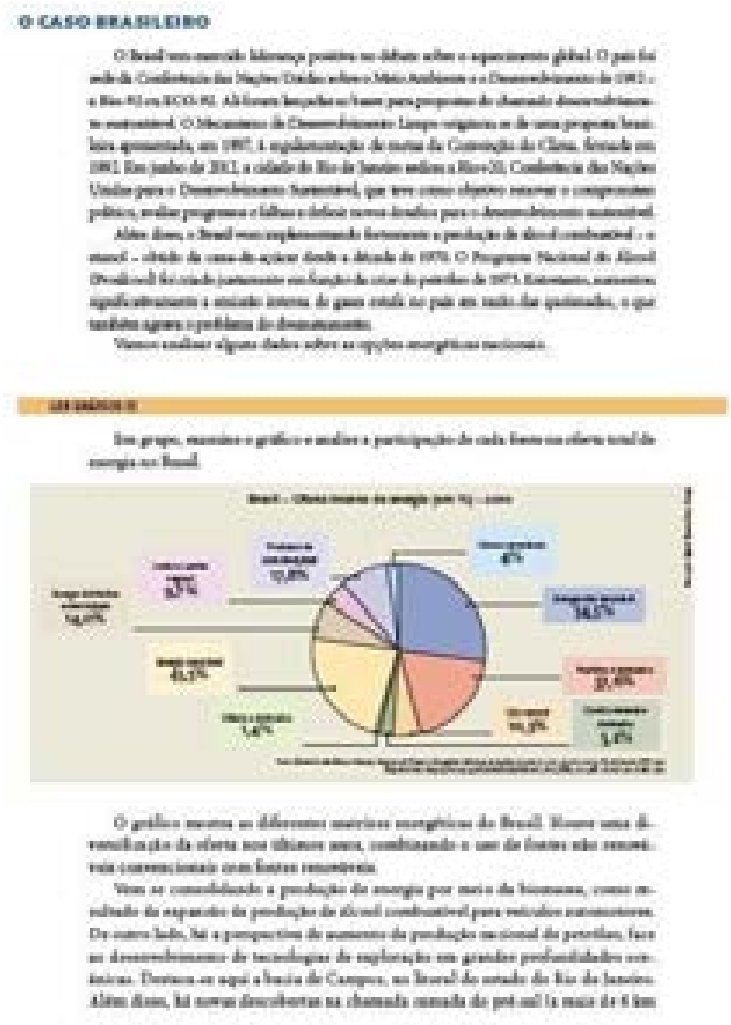

Figura 1 - Página 137, Livro coleção viver, aprender - Ciências humanas.

No exemplo acima, é possível observar como mostrar dados importantes para nossos alunos, como o consumo e produção de nossas fontes de energia de uma maneira simples e direta e que acima de tudo não seja cansativa para nossos alunos. O livro também faz uso de mapas temáticos onde vai expor dados de uma maneira mais simples. Ao utilizar este método que fundamenta a geografia tradicional, os autores nos mostram como é importante manter uma boa relação entre os métodos, pois mesmo prevalecendo o dialético, ele não abandona o hipotético-dedutivo, mostrando assim a importância da utilização de todos os métodos.

Existe também a presença do método Fenomenológico que é o estudo de um conjunto de fenômenos e como se manifestam, seja através do tempo ou do espaço. 0 método fenomenológico foi criado pelo filósofo Edmund Husserl. Assim, “O projeto fenomenológico se define como uma 'volta às coisas mesmas', isto é, aos fenômenos, aquilo que aparece à consciência, que se dá como seu objeto intencional." (SILVA, 2013, p. 64, apud JAPIASSU; MARCONDES, 2001, p. 101). É uma matéria que consiste em estudar a essência das coisas e como são percebidas no mundo pelas próprias pessoas. Este método leva em consideração a subjetividade de cada indivíduo e vai analisar os fatos de acordo com a experiência vivida em relação ao espaço vivido. O livro trabalha o método fenomenológico através do uso de músicas e análise de fotos que relatam nosso próprio cotidiano. 


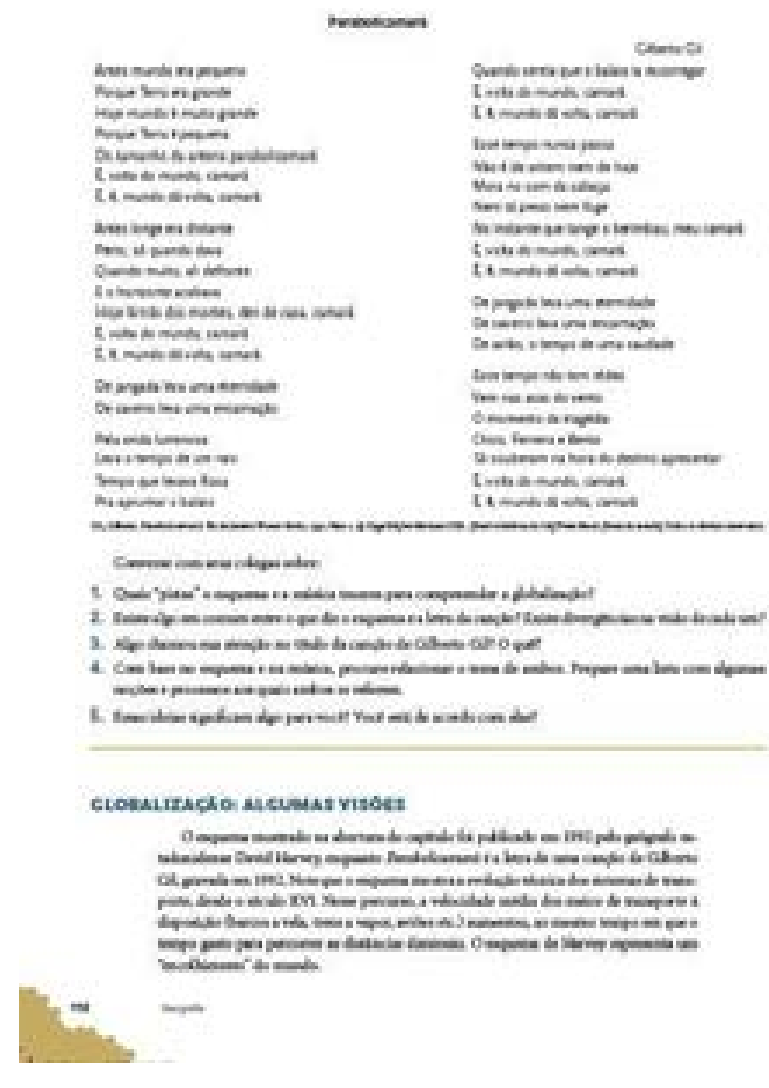

Figura 2: Página 112 - Livro coleção viver, aprender - Ciências humanas.

Ao utilizar a música como material e fonte de transmissão de conhecimento, ele vai levar o aluno a sentir o sentimento que a música quer transmitir para ele e leva o aluno a usar a sua própria percepção. Ao analisar as fotos propostas, o livro vai influenciar o aluno a perceber a mudanças propostas pelas imagens e levar o mesmo a fazer sua própria análise através de sua percepção individual.

Por último e como método mais utilizado no livro é o método dialético. Este método é uma forma de analisar a realidade a partir da confrontação de teses, hipóteses ou teorias e tem origem na Grécia antiga, com filósofos clássicos como Sócrates, Platão, Aristóteles e Heráclito. 0 livro adota este método como predominante devido ao público alvo que são alunos mais velhos e que são completamente capazes de fazer discussões mais específicas devido à idade que possuem e as suas experiências vividas. Dessa forma, "A Dialética em primeiro lugar é convite insistente à discussão e à prática, à criatividade, ao diálogo crítico e produtivo" (DEMO, Dialética e qualidade política, in Dialética hoje, 1990:134).

Ao utilizar a Dialética, o livro expõe os pontos existentes nas problemáticas tratadas no livro e leva o aluno a aprender a questionar os acontecimentos e os conhecimentos ao seu redor de uma maneira crítica, de uma maneira pensada para que tome atitudes mais racionais e não se deixe influenciar por conclusões distorcidas que são passadas para alienar a grande massa. 


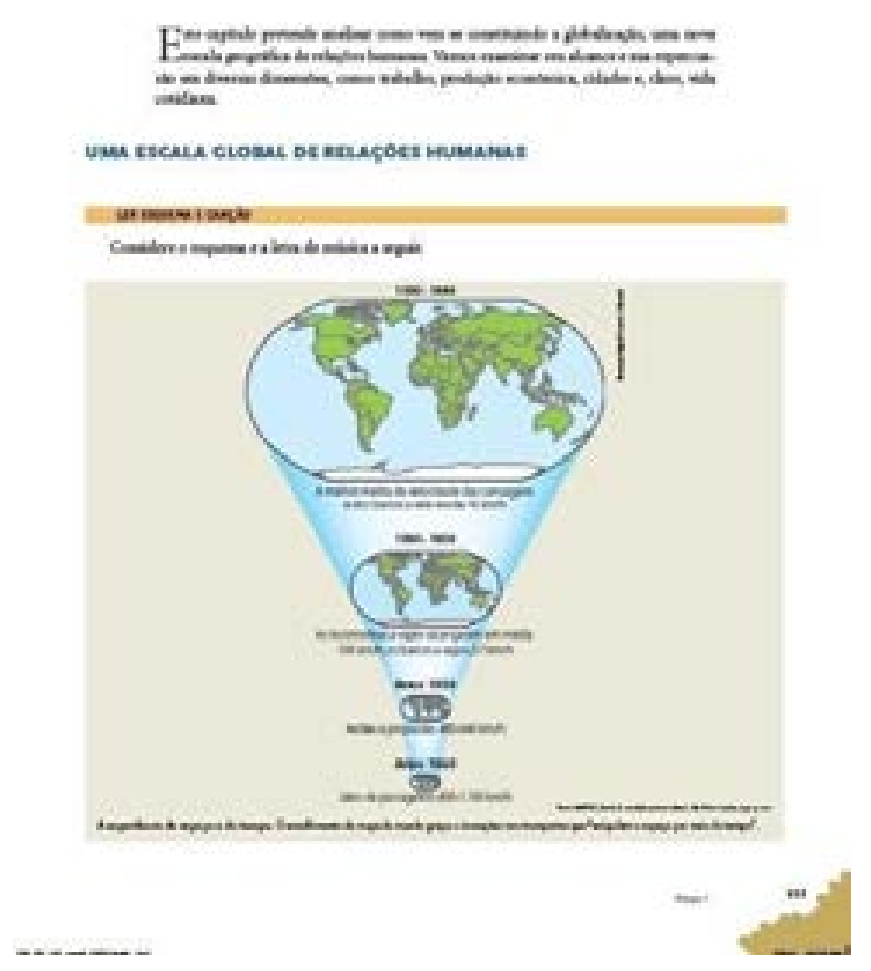

Figura 3: Página 111 - Livro coleção viver, aprender - Ciências humanas.

No exemplo retirado do livro, o autor leva o aluno a entender como a percepção do tamanho do mundo foi alterada de acordo com a evolução dos meios de transporte através da tecnologia. Na medida em que o homem desenvolve meios de transportes mais rápidos, ele pode percorrer grandes distâncias em um curto espaço de tempo e isso leva o aluno a visualizar este fato através do esquema apresentado pelo livro de maneira crítica.

\section{COMO TRABALHAR OS DIFERENTES MÉTODOS NO ENSINO DA GEOGRAFIA}

\section{Atividades propostas: Dialético}

0 método dialético é conhecido por ser um método crítico, é também o que embasa a geografia crítica. No caso especial do livro analisado, para alunos do EJA, este método se torna importante para que os alunos possam analisar as situações e assim formar uma opinião própria.

Para este método sugerimos algumas abordagens que possam vir a serem utilizadas pelos professores em sala de aula, onde trabalhem com educação para o ensino de jovens e adultos. O tema escolhido como exemplo para estas sugestões de abordagens foi a globalização, tema trabalhado no capítulo 9 do livro analisado. As atividades propostas como sugestão são: Debates em grupo, seminários temáticos e entrevistas. Tanto os trabalhos em grupo, quanto os seminários temáticos despertam bastante a curiosidade do aluno e desta forma os incentivam a buscar mais informações e isso contribui para sua formação acadêmica e para formação de opinião dos alunos, fazendo com que os mesmos se aprofundem no tema trabalhado para poder explicitar suas próprias opiniões de forma mais construtiva, possuindo embasamento para tal discussão. 
Ao utilizar as entrevistas, visamos aflorar o lado dialético do aluno, o pensamento crítico incentivando o aluno a refletir sobre como ele fará seu questionamento na busca do saber e da informação desejada. Desta forma, abrimos um "leque" de novas informações, que através das respostas e opiniões dos entrevistados levem o aluno a observar e tomar conhecimento de diferentes posicionamentos sobre o tema abordado em sua entrevista, fortalecendo também o respeito a opiniões diversas ajudando cada vez mais na construção social e acadêmica dos alunos.

\section{Atividades propostas: hipotético-dedutivo}

Propor atividades que estejam de acordo com o método hipotético-dedutivo em conjunto com o conteúdo do livro foi uma tarefa difícil, porque o livro quase não aborda este método com ferramenta primária, mas como um suporte para os outros métodos. Para um resultado mais próximo possível do ideal, buscamos analisar as características do método para buscar atividades que estivessem mais intrínsecas ao método e, além disso, buscamos atividades mais adequadas para as características do público alvo, alunos do EJA. As atividades propostas param se trabalhar com este método são: o Quiz e as pesquisas de campo.

Para se utilizar o Quiz, dispondo das características enciclopedista, conteudista e de memorização. Propomos uma "dinâmica" com a utilização de um Quiz em forma de jogo entre grupos para uma melhor integração da turma. As perguntas devem ser selecionadas dentre os assuntos abordados ao logo do ano em sala de aula e devem ter um caráter neutro. Após obter as respostas, os alunos deveram montar gráficos para demonstrar a média de erros e acertos dos alunos da turma.

Por fim, indicamos as pesquisas de Campo. Como o livro é destinado à alunos que normalmente possuem compromissos durante o dia e vão para a aula à noite, uma pesquisa de campo demanda tempo demais dos alunos durante o dia, propomos que esta atividade seja realizada dentro da própria escola, no horário de aula. O objetivo desta atividade é coletar dados para uma análise quantitativa, desta maneira os estudantes podem criar gráficos e tabelas se apoiando no método, criando hipóteses para apoiar os métodos dialético e fenomenológico.

\section{Atividades propostas: Fenomenológico}

Uma proposta de método fenomenológico para ensinar globalização no EJA é a roda de conversa. Onde todos os atores compartilham experiências vividas, discutem sobre o dia a dia de cada um e expõem seus conhecimentos de mundo. Outra forma de abordagem tem bastante aceitação em outras áreas. É a projeção de filmes relacionados à temática. Quando ao final de cada exibição o aluno é incentivado a demonstrar através de texto as similaridades da ficção com o mundo real.

Há também outra proposta de método que pode ser muito explorada pelos corpos docente e discente. A produção literária faz com que os alunos desenvolvam suas habilidades através da produção de cordéis e ao mesmo tempo os mesmos pratiquem a disseminação da cultura popular divulgando o resultado de seus trabalhos. Como a faixa etária de EJA advém de um misto de pensamentos geográficos individuais e em sua maioria são pessoas com tempo limitado para a realização de aula de campo, a exposição fotográfica é um método que por sua vez, pode ser trabalhado no dia a dia do estudante, onde o mesmo pode fazer as capturas das imagens durante o período extraclasse e após uma seleção criteriosa e debatidas em aula, essas fotos sejam expostas em diversos eventos da própria escola. 
Para se trabalhar o tema globalização, podemos realizar pesquisas de músicas e vídeos sobre o assunto para serem executados e discutidos em aula. Logo em seguida, pode-se estimular a criatividade de modo que os alunos produzam paródias, esquetes e curtas de vídeos a serem exibidos em outras turmas da instituição.

\section{CONSIDERAÇÕES FINAIS}

Em decorrência dos fatos expostos durante esta pesquisa, notamos como é importante se fazer uma completa análise no livro didático que pretendemos usar em nossa docência, pois devemos escolher um material que se adeque as necessidades de nossos alunos e assim nos proporcione lograr êxito em nossa missão como professores. Além da escolha do livro os próprios professores devem ser como água e se misturar e contornar as adversas situações que iram surgir em sala de aula e assim encontrar formas alternativas no trabalho didático, para que possamos manter o interesse de nossos alunos nos diversos temas trabalhados em sala de aula para que eles possam visualizar como estes temas estão inseridos em sua própria realidade.

Nesta análise do livro didático da coleção Viver e Aprender: Ciências humanas- Ensino Médio- Tempo, Espaço e Cultura, voltados para alunos do EJA, se propuseram como objetivo identificar os métodos utilizados no mesmo, e propor atividades ou abordagens com os métodos para o tema Globalização encontrados no livro. Foi uma experiência muito rica, pois nos fez analisar o livro de uma forma diferente, encontrando traços que marcam a presença dos métodos. Utilizamos também outras referências além do livro analisado, onde fizemos com que a análise se tornasse bastante rica e interessante.

\section{REFERÊNCIAS}

1. BOCHENSKI, M. J. A fenomenologia de Edmund Husserl. Tradução: Antônio Pinto de Carvalho, in A filosofia contemporânea ocidental, Herder, 1968.

2. BRASIL. Decreto $N^{\circ} 7.084$, de 27 de janeiro 2010. Dispõe sobre o programa de material didático e dá outras providências. Diário Oficial da União: Brasília, 27 de janeiro de 2010, Edição extra; Página 3.

3. VIANA, J., CHAVES, J. M, BERNARDI, F. N. Livro didático como instrumento de apoio para construção de propostas de ensino de ciências naturais. 2009. Encontro Nacional de Pesquisa em Educação em Ciências. Florianópolis, 8 de novembro de 2009.

4. UNIVERSIDADEANHEMBI MORUMBI. Metodologia de Pesquisa Cientifica. Disponível em: $<$ http://www2.anhembi.br/html/ead01/metodologia_pesq_cientifica_80/lu04/lo4/inde x.htm>. Acesso em: 29/10/2016.

5. BRASIL, Ministério da Educação. Parâmetros Curriculares Nacionais - PCN HISTÓRIA E GEOGRAFIA. 1997. Brasília: 1997. 
6. MINISTÉRIO DA EDUCAÇÃO. Proposta curricular - Educação para jovens e adultos. 2001. Disponível em:

<http://portal.mec.gov.br/secad/arquivos/pdf/eja/propostacurricular/ primeirosegmento/propostacurri cular.pdf $>$. Acesso em: 29/10/2016.

7. SAUER, Carl Ortwin. (1983): The morphology of landscape. In: LEIGHLY, J. (org.), Land and Life - A Selection from the Writings of Carl Ortwin Sauer. Berkeley: University of California Press, p. 343.

8. GADOTTI, Moacir; ROMÃO José E. Diretrizes Nacionais. In: GADOTTI, Moacir; ROMÃO José

E. (org). Educação de jovens e adultos: teoria, prática e proposta. São Paulo: Cortez: Instituto Paulo Freire, 2001, p. 119. 1989.

9. HUSSERL, Edmund. A ideia da fenomenologia. Lisboa; Rio de Janeiro: Edições 70,

10. JAPIASSU, Hilton; MARCONDES, Danilo. Dicionário básico de Filosofia. $3^{\mathrm{a}}$ ed. Rio de Janeiro: Jorge Zahar, 2001.

11. SILVA, Márcio Tadeu da. Uma análise crítica do método fenomenológico e a sua relação com as "geografias" humanistas; Geografia em questão, ISSN 2178-0234, V.06, N. 02, 2013 págs. 64.

12. CORTI, A.P.; SANTOS, A.L.P.; MENDES, S.; CARROCHANO, M.C.; FERNANDES, M.L.B.;

13. CASTELLI, R.JR.; GIANSANTINI, R. Tempo, espaço e cultura: Ciências Humanas: Ensino Médio: Educação Para Jovens e Adultos. $1^{\circ}$ Edição. São Paulo: Global, 2013. 467 p. (Coleção Viver, Aprender). 